chorionic villi samples in the first trimester of pregnancy. Hum Genet 1983;63:349-57.

2 Schweizer D. Ambros P, Andrle M. Modification of DAPI banding on human chromosomes by prestaining with a DNAbinding oligopeptide, distamycin A. Exp Cell Res 1978:111: 327-32.

"Sachs E, Van Hemel J, Galjaard H, et al. First trimester chromosomal analysis of complex structural rearrangements with RHA-banding on chorionic villi. Lancet 1983;ii:1426.

Correspondence and requests for reprints to Dr J O Van Hemel, Department of Clinical Genetics, University Hospital, PO Box 1738, 3000 DR Rotterdam, The Netherlands.

\section{A three way translocation in mother and daughter}

A woman presented with a history of six miscarriages occurring between the 6th and 14th weeks of gestation. Chromosome analysis revealed a complex rearrangement, with segments of three chromosomes translocated in 'circular' fashion: most of $2 \mathrm{q}$ onto $18 \mathrm{q}$; some of $18 \mathrm{q}$ onto $11 \mathrm{p}$; and the tip of $11 \mathrm{p}$ onto $2 \mathrm{q}$. Her karyotype can be expressed as $46, \mathrm{XX}, \mathrm{t}(2 ; 11 ; 18)(2 \mathrm{pter} \rightarrow 2 \mathrm{q} 13:: 11 \mathrm{p} 15 \cdot 3 \rightarrow$ 11 pter; 11 qter $\rightarrow 11$ p 15.3::18q21 $11 \rightarrow 18$ qter $; 18$ pter $\rightarrow$ $18 \mathrm{q} 21 \cdot 1:: 2 \mathrm{q} 13 \rightarrow 2 \mathrm{qter})$. A partial karyotype is shown in the figure. Because both her parents had normal chromosomes, it can be assumed that the rearrangement arose de novo. Her two pregnancies which went to term produced phenotypically normal daughters, one with the same balanced three way translocation, the other with a normal karyotype.

Complex chromosomal rearrangements are rare. ${ }^{1} 2$ In most cases where the translocation is familial, it is the mother who is the transmitting parent, ${ }^{1}$ in one family through three generations. ${ }^{3}$ Oogenesis may be a more robust mechanism of gamete formation than spermatogenesis in the presence of this particular disruptive influence. A maturation arrest at the secondary spermatocyte stage has been demonstrated in one sterile male heterozygote. $^{2}$

If, at pachytene, pairing of homologous chromosomal segments is successfully achieved, this will lead to the formation of a hexavalent configuration. At the first meiotic division, then, $3: 3,4: 2,5: 1$, and $6: 0$ disjunctions are theoretically possible. The great majority of theoretically possible segregant gametes could be expected to give rise to conceptuses with such an unbalanced genetic complement that loss would occur in early pregnancy, often in very early pregnancy ('occult abortion'). Given the enormous theoretical range of gamete abnormality, and bearing in mind the modifying factor of selection against unbalanced forms, the fact that our proband had two conceptuses arising from alternate 3:3 segregation out of

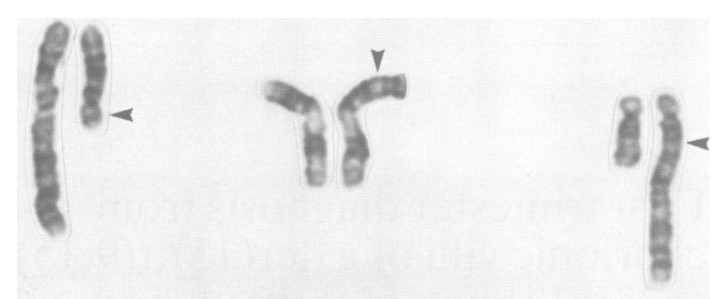

FIGURE Partial karyotype. The normal homologue is the left of each pair, and the derivative chromosome the right. Arrows indicate breakpoints.

eight recognised pregnancies might indicate this category of chromosomal distribution to be favoured. In our advice to her 19 year old heterozygous daughter, we have indicated the high probability of her having miscarriages in the future, but have also counselled cautious optimism that the same good fortune that attended two of her mother's meioses may also dwell in her (although advising that a heterozygous son might possibly be sterile). Prenatal diagnosis would be indicated to detect an unbalanced but viable chromosomal complement.

R J M Gardner, N A Monk, G J Allen, AND M I PARSLOW Department of Paediatrics and Child Health, University of Otago;

Department of Laboratory Services, Dunedin Hospital, Dunedin; and Department of Community Health, University of Auckland, Auckland, New Zealand.

\section{References}

1 Kleczkowska A, Fryns JP, van den Berghe H. Complex chromosomal rearrangements (CCR) and their genetic con sequences. J Genet Hum 1982;30:199-214.

2 Joseph A, Thomas IM. A complex rearrangement involving three autosomes in a phenotypically normal male presenting with sterility. J Med Genet 1982;19:375-6.

${ }^{3}$ Creasy MR, Crolla JA. Complex chromosomal rearrangements. Clin Genet 1981:19:481-2.

Correspondence and requests for reprints to Mrs $\mathrm{N}$ 윽 A Monk, Cytogenetics Laboratory, Department of $\rightarrow$ Laboratory Services, Dunedin Hospital, Dunedin, New Zealand.

\section{Familial inv(1)(p36·3q12) associated with sterility}

Chromosomal abnormalities are among the more impor- $\mathbb{D}$ tant causes of reproductive failure. Three instances of $\stackrel{?}{?}$ familial pericentric inversion of chromosome 1 associated $\square$ with sterility have been reported. ${ }^{1-3}$ In this paper we

Received for publication 31 October 198t.

Revised version accepted for publication 21 January 1985 
describe what is, to our knowledge, the first familial case of pericentric inversion of chromosome 1 involving the whole of the short arm and associated with infertility.

The proband was a male aged 35 who came to our laboratory because of sterility. He reported a 33 year old brother who had been married for two years without children. Both patients had normal phenotypes and no history of testicular pathology. Semen analysis showed severe oligozoospermia in both and the few spermatozoa present were immotile. The patients refused testicular biopsy.

Chromosome preparations in the proband and his brother, obtained from peripheral blood lymphocytes, were examined after $\mathrm{G}, \mathrm{C}$, and high resolution $\mathrm{R}$ banding. $\mathrm{G}$ and $\mathrm{R}$ banding revealed in both an inverted short arm of chromosome 1 with the centromere located near the terminal part of the chromosome. $\mathrm{C}$ banding showed two blocks of $\mathrm{C}$ heterochromatin, the smaller one located in a subterminal position. This suggested that the breakpoints were at $1 \mathrm{p} 36 \cdot 3$ and $1 \mathrm{q} 12$ (fig 1 ).

This unusual pericentric inversion was also found in the mother of the proband, inv( 1$)(p 36 \cdot 3 q 12)$, showing that the inverted chromosome was inherited without meiotic recombination in the inverted segment. The karyotype of II.5 was normal (fig 2).

In this case, as in the three others previously reported, it is reasonable to assume that there may be an association between the inversion and failure of spermatogenesis.

This work was supported by a grant from INIC to the Center of Human Genetics and Social Biology, University of Oporto. We thank Mr J M Barros for his skilful help with the chromosome photographs.

Alberto Barros* ${ }^{*}+$ M Carmo Tavares*, M Paula Gomes*, and M PurificaÇão Tavares*

*Department of Medical Genetics, Faculty of Medicine,

University of Oporto; and

+Department of Obstetrics,

$S$ João Hospital, Oporto, Portugal.

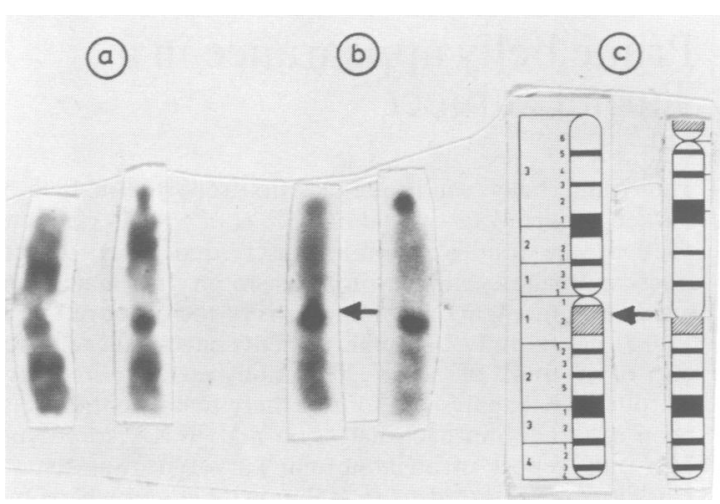

FIG 1 (a) $G$ banding (inv on right). (b) $C$

banding (inv on right). (c) Diagram of

chromosome 1 with the proposed breakpoints

(arrow) and the resulting inverted chromosome (right).

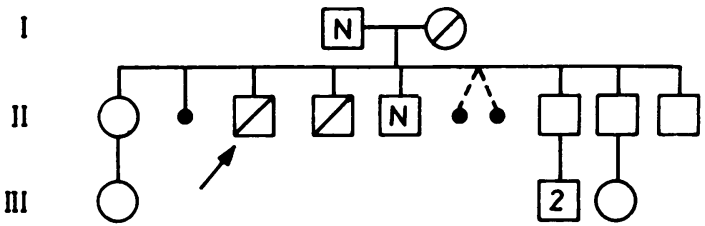

Inversion carriers

N (N) Normal karyotype

is Twins, zygosity unknown

Proband

FIG 2 Family pedigree.

\section{References}

1 Giraldo A. Silva E, Martinez I. Campos C, Guzmán J. Pericentric inversion of chromosome 1 in three sterile brothers. Hum Genet 1981;58:226-7.

2 Tóth A, Gaál M. Sára G, Lázló J. Pericentric inversion of chromosome 1 in an azoospermic man. $J$ Med Genet 1982;19:303-5.

${ }^{3}$ Rivera H, Alvarez-Arratia MC, Moller M. Díaz M. Cantú JM Familial inv(1)(p35.00q21.3) associated with azoospermia. Hum Genet 1984;66:165-7.

Correspondence and requests for reprints to Dr Alberto Barros, Department of Medical Genetics, Faculty of Medicine, University of Porto, 4200 Porto, Portugal.

\section{Complex translocation involving chromosomes $\mathrm{Y}, 1$, and 3 resulting in deletion of segment $3 \mathrm{q} 23 \rightarrow \mathrm{q} 25$}

The proband was the first child of non-consanguineous parents. He has a younger, phenotypically normal sister. Birth weight was $1.9 \mathrm{~kg}$ and he had respiratory distress at birth. Psychomotor development was delayed. His height and weight were on the 3 rd centile and his head circumference was below the 3 rd centile. He started to walk at $21 / 2$ years and could say a few words at $31 / 2$ years. IQ was assessed to be around 75 to 80 .

The proband had microbrachycephaly, a flat occiput, depressed supraorbital ridges, and flat nasal bridge. Palpebral fissures were narrow and upward slanting. There

Received for publication 31 December 1984.

Revised version aceepted for publication 19 March 1985 